\title{
A Conceptual Governance Framework for Climate Change Adaptation and Disaster Risk Reduction Integration
}

\author{
Giuseppe Forino $^{1} \cdot$ Jason von Meding $^{1} \cdot$ Graham J. Brewer $^{1}$
}

Published online: 22 December 2015

(C) The Author(s) 2015. This article is published with open access at Springerlink.com

\begin{abstract}
Climate change adaptation (CCA) and disaster risk reduction (DRR) have similar targets and goals in relation to climate change and related risks. The integration of CCA in core DRR operations is crucial to provide simultaneous benefits for social systems coping with challenges posed by climate extremes and climate change. Although state actors are generally responsible for governing a public issue such as CCA and DRR integration, the reform of top-down governing modes in neoliberal societies has enlarged the range of potential actors to include non state actors from economic and social communities. These new intervening actors require in-depth investigation. To achieve this goal, the article investigates the set of actors and their bridging arrangements that create and shape governance in CCA and DRR integration. The article conducts a comprehensive literature review in order to retrieve main actors and arrangements. The article summarizes actors and arrangements into a conceptual governance framework that can be used as a backdrop for future research on the topic. However, this framework has an explorative form, which must be refined according to site- and context-specific variables, norms, or networks. Accordingly, this article promotes an initial application of the framework to different contexts. Scholars may adopt the framework as a roadmap with which to corroborate the existence of a theoretical and empirical body of knowledge on governance of CCA and DRR integration.
\end{abstract}

Giuseppe Forino

Giuseppe.forino@newcastle.edu.au

1 School of Architecture and Built Environment, University of Newcastle, University Drive, Callaghan, NSW 2308, Australia
Keywords Actors - Climate change adaptation - Climate change risk - Disaster risk reduction - Governance

\section{Introduction: Integration of Climate Change Adaptation in Disaster Risk Reduction}

Worldwide, climate change intensifies some of the hazards affecting social systems and weakens resilience in facing uncertainty and disasters (O'Brien et al. 2006). It also contributes to increased climate extremes and exacerbates adverse impacts (Birkmann and Mechler 2015). Climate change is just one factor influencing certain hazards; it can contribute to disasters where vulnerability and exposure exist, but it is not necessarily the most prominent. Nonclimatic factors such as globalization, earthquakes, injustice, lack of livelihood opportunities, overexploitation of resources, and epidemics converge to mostly affect people with limited access to resources for dealing with climate change-related challenges. These people tend to be most vulnerable and have multiple exposures to multiple simultaneous threats (Kelman et al. 2015). Awareness is required about the connection of climate change with other global issues (IPCC 2012, 2014; Birkmann and Mechler 2015; Kelman et al. 2015).

Two milestone reports by the Intergovernmental Panel on Climate Change (IPCC), Managing the Risk of Extreme Events to Advance Climate Change Adaptation (IPCC 2012) and the contribution of Working Group II to the IPCC Fifth Assessment Report (IPCC 2014) urge a risk perspective for assessing the different climate change-related threats (Birkmann and Mechler 2015). Given that climate change and associated processes are fully embraced by disaster-related efforts, a prudent place can be 
posed for considering climate change adaptation (CCA) as a subset within disaster risk reduction (DRR) (Kelman and Gaillard 2010; Mercer 2010; Kelman et al. 2015). For this article's purpose, CCA in social systems is "the process of adjustment to actual or expected climate and its effects, in order to moderate harm or exploit beneficial opportunities" (IPCC 2012, p. 556), while DRR is "a policy goal or objective, and the strategic and instrumental measures employed for anticipating future disaster risk, reducing existing exposure, hazard, or vulnerability, and improving resilience" (IPCC 2012, p. 558). Both CCA and DRR aim: (1) to manage hydrometeorological hazards through vulnerability and exposure reduction, resilience increase, and risk transfer and sharing (IPCC 2012); (2) to reduce the impacts of climate-related disasters and associated risks; and (3) to promote proactive, holistic, and long-term approaches to disaster management (Thomalla et al. 2006). However, CCA and DRR originated and are maintained in different communities of research and practice, use different approaches and conceptual frameworks, and tend to be planned, implemented, and funded by different government agencies and organizations (Birkmann and von Teichman 2010; Djalante and Thomalla 2012). Differences also exist in technical language and in approaches to project implementation. Meanwhile, institutional, financial, and political barriers inhibit cross-disciplinary and holistic collaboration and programs (Gero et al. 2011b). These differences create a "silo" mentality of separated and isolated paths among CCA and DRR communities (Gero et al. 2011b; IPCC 2012; Howes et al. 2015).

Attention is significantly increasing about the need for a coherent integration of CCA and DRR (Begum et al. 2014; Rivera and Wamsler 2014). This integration is part of a mainstreaming process involving modifications to specific core operations in order to incorporate and indirectly act upon new topics (Rivera and Wamsler 2014). Accordingly, CCA is the aspect to be integrated into the core DRR operation. CCA and DRR integration could provide benefits at all scales, minimize overlap and duplication of projects and programs (Nalau et al. 2015), and move beyond vulnerability and resilience towards a vision of DRR that ends separation between the two issues and promotes working together towards simultaneous and common goals (Kelman et al. 2015).

International organizations have made efforts to promote CCA and DRR integration. In 2005, the World Conference on Disaster Reduction (WCDR) (UNISDR 2005) adopted the Hyogo Framework for Action 2005-2015 (HFA), which calls for multidisciplinary and future-oriented approaches to DRR when considering climate change. In 2007, the United Nations Framework Convention on Climate Change (UNFCCC 2007) adopted the Bali Action Plan, which recognizes the necessity of harnessing DRR strategies for extreme weather events. Also UNISDR (2009) recommended a functional linking of CCA and DRR within the context of poverty reduction and development.

Recent IPCC's reports (IPCC 2012, 2014) present current guidelines for CCA and DRR integration. Three important policy processes for CCA and DRR integration culminate in 2015, so it may be a milestone year (Mysiak et al. 2015). In March, the Sendai Framework for Disaster Risk Reduction 2015-2030 (SFDRR) updated the HFA and established a voluntary pathway for future DRR strategies (UNISDR 2015). Identifying priorities in SFDRR would have represented a significant step toward an effective DRR implementation, as well as an achievement for the implementation of other important policy appointments such as the sustainable development goals (SDG) and the new greenhouses gas (GHG) targets (Briceño 2015). Unfortunately, because the SFDRR positioned multihazard disaster risk management under a regime of responsibilities that is common to yet differentiated from those of climate organizations (such as UNFCCC), it continues to separate CCA and DRR communities, processes, and targets (Mysiak et al. 2015). The SFDRR also does not explain how to establish and maintain in practice cross-sectoral coherence and coordination between CCA and DRR (Kelman 2015). In September, the United Nations (UN) ratified the SDG. Among the others, the Goal 13 aims to "take urgent actions to combat climate change and its impacts through strengthening resilience and adaptive capacity to climate-related hazards" (United Nations Department of Economic and Social Affairs 2015), which supports the requirement of linking CCA and DRR integration to the development agenda (Schipper and Pelling 2006; Ireland 2010). But Satterthwaite (2015) notes that no indication has been reported about how, by whom, and with what funding the SDG will be realized. Finally, in December, the UNFCCC began to pursue a legally binding treaty in relation to GHG emissions. Expectations for a positive result are uncertain, so 2015 runs the risk of further inaction (Mysiak et al. 2015).

To investigate CCA and DRR integration, governance has recently been considered as a major framework, although it still represents a confounding topic in the CCA and DRR literature (Gero et al. 2011b). Some authors have discussed emerging themes of governance related to actors, interactions, decision-making, or legitimacy, among others. For Australia, Howes et al. (2015) use the networked governance (NG) framework to analyze opportunities for public officers facing cost-shifting and jurisdictional challenges; for Indonesia, Djalante (2013) uses the earth system governance (ESG) framework to investigate barriers and opportunities for government organizations and ministries; for Fiji and Samoa, Gero et al. (2011b) use the ESG to 
investigate challenges and opportunities of CommunityBased Initiatives (CBIs).

No single approach represents a panacea for simplifying the reality of governance (Ostrom 2008; Duit et al. 2010; Gero et al. 2011a). This article contributes to this current body of knowledge: it reviews the field's literature, highlights main actors and bridging arrangements, and provides a comprehensive picture of governance in CCA and DRR integration. This article is organized around an interactive understanding of actors, bridging arrangements, and their governance. Section 2 provides an overview of the most salient characteristics of governance. Section 3 reviews the literature and retrieves the main actors and arrangements of governance in CCA and DRR integration. Section 4 summarizes the results of the review into a conceptual framework for governance in CCA and DRR integration and provides a discussion about limitations and opportunities. Section 5 concludes the article with recommendations for scholars, policymakers, and practitioners.

\section{Towards Governance: Reform in the Top-Down Modes of Governing Public Affairs}

Generally, the term governance describes the neoliberal reform in traditionally top-down modes of governing public affairs (Jessop 1998; Lemos and Agrawal 2006). Since the 1970s, globalization, international trade regimes, and rapid technological and environmental changes have reformed traditional state-market-society relations (Jessop 1998; Gero et al. 2011b; Djalante 2013). The reform redistributed local and global accountability and responsibilities from the state across a broader range of non-state actors from market and society (Rhodes 1996; Jessop 1998; Rhodes 2007). State actors do not just manage public affairs, but also coordinate and join public and private resources towards public goals; market actors put competitive pressure on service provision by the state, simultaneously seeking to safeguard their profitability goals; social actors provide for individual/community skills and site-based and place-specific knowledge and resources to state actors (Lemos and Agrawal 2006).

The reform mirrored the intensification of societal complexity and the growing functional differentiation within social systems (Jessop 1998). Ideally, no single actor has sufficient knowledge or potential to dominate unilaterally, and the distinction between actors is blurred (Rhodes 1996; Kooiman and Jentoft 2009). Actors develop their complex logic and are operationally independent from each other. Nevertheless, actors are structurally coupled and coordinated due to systemic and dynamic interdependences, temporally and spatially evolving (Rhodes 1996;
Jessop 1998). These interdependences constitute a set of formal and informal linkages, structured around shared interests in exchanging resources to achieve goals, maximizing their influence over outcomes, and avoiding full dependence on other actors (Rhodes 1996, 2007). These linkages are contained within nonhierarchical, interorganizational, self-organizing, coordinated, and context-mediated networks (Kooiman and Jentoft 2009). Shared values and norms, as well as trust and diplomacy, become essential within these networks (Rhodes 2007).

The architecture of governance is dynamic, continuously evolving, and characterized by complexity, uncertainty, and ambiguity (Duit and Galaz 2008; Duit et al. 2010; Renn 2015). Complexity emerges due to the multiple factors affecting cause/effect relationships, often challenging common rationales; uncertainty reduces confidence in the estimated cause/effect chain that demarcates the best available knowledge at a specific time and its perfectibility; ambiguity is related to the different values assigned by different actors to the inputs/outputs of an event (Renn 2015).

Governance confronts the diversity, dynamics, and complexity of societal systems. It recognizes that no single agency can realize effective outcomes in governing by itself. Also governance results from the increasing spread of globalized and neoliberal practices, and from a belief that alternative modes can provide for better outcomes (Lemos and Agrawal 2006; Prno and Slocombe 2012). Governance is the mean of interactions and networks of actors, their sometimes conflicting objectives, and the instruments chosen to solve societal problems and to create societal opportunities within a particular area (Duit and Galaz 2008; Kooiman and Jentoft 2009; Duit et al. 2010). Governance is influenced by the multiple and contextual actions, norms, and behaviors of groups or individuals, which simultaneously operate following formal or informal pathways.

\section{Findings: Actors and Arrangements of Governance in CCA and DRR Integration}

This section reviews literature about governance in CCA and DRR integration in order to highlight the main actors and related bridging arrangements that create and shape governance. Lemos and Agrawal (2006) group actors into three main domains: national and subnational governments (state actors' domain), private sector (market actors' domain), and communities (social actors' domain). Through specific bridging arrangements, actors interact, incorporate, and mobilize joint actions that seek to address the weaknesses of an actor while simultaneously exploiting the strength of the others (Prno and Slocombe 2012). These arrangements are: 
public-private partnerships (PPPs) between state and market actors, private-social partnerships (PSPs) between market and social actors, and comanagement (CM) between state and social actors (Lemos and Agrawal 2006). However, boundaries between and within actors, domains, and arrangements in governance are often not clearly definable or do not exist. In this article, some concepts are simplified for the sake of synthesis.

\subsection{State Domain}

State actors include multiple levels and sectors of government (national, regional, and local). In CCA and DRR integration, state actors use their portfolio of assets and liabilities with which to manage legislation, resource allocation, planning and implementation, as well as goods and services provision, income redistribution, and economy stabilization in order to ensure the well-being and safety of citizens (IPCC 2012). However, climate change may put these functions at risk.

\subsubsection{Collaboration in Multilevel Governments and Specific Organizations}

Collaboration among multiple levels of government increases the effectiveness of CCA and DRR integration (Begum et al. 2014). Often the design of some national governance systems does not facilitate collaboration. For example, in Australia the current architecture of the federal system provides limited space for tackling complex issues such as climate change and risks. Rather, the political system tends to encourage vagueness, duplication of responsibilities, and conflicts (Heazle et al. 2013; Howes et al. 2015). Nevertheless, the Australian government is making efforts to develop a multilevel collaborative approach. The National Climate Change Adaptation Framework (2007) was designed to support collaboration between federal, state, and local governments. From this departure point, other instruments have expanded these efforts. These institutional arrangements include the National Partnership Agreement on Natural Disaster Resilience (2009), the National Emergency Risk Assessment Guidelines (2010), and the National Strategy for Disaster Resilience (2011) (see also Howes et al. 2015). In Fiji, political tensions make governance a contested topic with considerable impact on CCA and DRR outcomes (Gero et al. 2011b). For example, the formal state and the traditional structures follow parallel paths, which limits collaboration and coordination in implementing CCA and DRR activities (Becker 2012).

Collaboration is also necessary among specific CCA and DRR organizations if common goals are to be targeted simultaneously (Birkmann and von Teichman 2010). For example, in the Southern African Development Community region, limited collaboration among parallel CCA and DRR organizations caused the dispersion of CCA and DRR activities and a problematic resource allocation (Becker et al. 2013). Similarly, in Indonesia, a reorientation of national government ministries and mandates is required due to major inconsistencies in CCA and DRR structures (Djalante and Thomalla 2012). To achieve this integration goal, mechanisms such as multistakeholders platforms (MSPs) have been used to enhance coordination and collaboration among multiple stakeholder actors at different levels, all with different agendas, as well as to create space for learning and sharing. But technical capacity and the ability to generate funding are still challenging for MSPs (Djalante 2012; Djalante et al. 2013).

\subsubsection{Strategies, Policies, and Plans}

Strategies, policies, and plans are among the principal ways the state promotes CCA and DRR. However, strategies, policies, and plans should avoid separation and target common goals to increase effectiveness against climateand climate change-related hazards (Porfiriev 2015). For example, some national governments are drafting and adopting adaptive strategies or plans such as national adaptation strategies, national adaptation programs of action (NAPAs), or strategic national action plans (SNAPs). However, linking these strategies or plans to DRR needs to be improved. Many of the least developing countries (LDCs) identified DRR as an urgent problem, but just 24 of 38 LDCs that submitted NAPAs to the UNFCCC have called for immediate action in DRR; only seven of the 24 have requested funding for capacity building and preparedness measures (Birkmann and Pardoe 2014).

National sectorial strategies, policies, and plans have to include CCA and DRR in their goals (UNISDR 2009). For example, incorporating CCA and DRR within urban policies allows identification and assessment of urban climaterelated vulnerabilities, as well as develops plans and establishes climate change-related priorities (Huq et al. 2007; Dodman and Satterthwaite 2008; Rivera and Wamsler 2014). The Headline Climate Change Adaptation Strategy of Durban has addressed specific climate changerelated vulnerabilities for several urban sectors by promoting the involvement of local communities in risk and vulnerability mapping (Dodman and Satterthwaite 2008; van Niekerk 2015). Similar evidence also exists for water and health policies. In West Africa, projects for improving water and health management have established collaborative policies among climate change, water resources, and health management efforts that target adaptive strategies and cope with drought and flood risk (Cissé 2013). 
Also CCA and DRR policies are important to improvement of the whole body of national policies. Mercer et al. (2014) claim that the efforts towards a national policy structure in Timor-Leste would greatly benefit from establishing policies that target DRR by including CCA. Once established, the CCA/DRR policy nexus can be linked to wider policies in agriculture, health, infrastructure, education, and economic development.

\subsubsection{Scientific Organizations}

Scientific organizations range from specialized research centers and universities to multilateral organizations. They are international in nature, but closely collaborate with state actors that promote national initiatives and programs. Scientific organizations are necessary in CCA and DRR integration (IPCC 2012). They support policies, research, and actions related to climate change and disasters, build cooperative networks with and among actors, and translate scientific evidence for a wider range of users (Thomalla et al. 2006; GDCRR 2011). Among scientific organizations, multilateral organizations promote international efforts, usually have governmental membership, and focus on development and aid to recipient countries from international organizations, such as the United Nations and the European Union, and development banks, for instance the World Bank (see also Mitchell and van Aalst 2008). Bilateral organizations promote national efforts and focus on intragovernmental relationships; this is often the case of richer governments supporting poorer ones. Multilateral and bilateral organizations also supply financial, technical, and strategic support to governments with limited resources (Thomalla et al. 2006; IPCC 2012).

\subsubsection{CCA and DRR Practitioners}

Climate change and disaster practitioners support CCA and DRR integration mainly through using, disseminating, and communicating information and responses (Marincioni 2007). Climate change expertise is usually found in meteorological, environmental, and energy agencies and university departments, while disaster managers are typically found in disaster management authorities and multilateral agencies (Birkmann and von Teichman 2010; Birkmann and Pardoe 2014).

\subsection{Market Domain}

Market actors range from private individual traders to multinational corporations. Some market actors admit an increase in the intensity and frequency of climatic hazards, believing that climate change is real and has an anthropogenic component (for example, GHG). However many people who deny the reality of climate change consider any climate variation to be part of natural climate cycles unlinked to human activities or the burning of fossil fuels (Johnson 2015). Market actors can be either affected by or generators of increased climate-related risks (Twigg 2001; IPCC 2012). The damage caused by climate change can be direct, such as damage to and loss of personnel, assets, and infrastructure, or indirect, such as access problems, disruption of supplies and labor, and changes in markets. Alternatively, market actors may contribute to generate or increase risks through: (1) direct actions, such as the construction of unsafe facilities and/or their placement in areas at risk, degradation and environmental pollution, and the use of hazardous materials; and (2) indirect actions that increase exposure to risks in production and supply chains, and relocate workers to risk-prone areas. In both cases, consequences are usually transferred from the private to the public sector or from one economic sector to another (Agrawala et al. 2011; Sarmiento et al. 2014).

Market actors may enact self-regulation and self-monitor mechanisms as a way to cope with climate changerelated risks (Lemos and Agrawal 2006), for example, by promoting the reduction of GHG emissions through reduced energy consumption, by purchasing "low-carbon" or renewable energy, or by increasing efficiency (Bradford and Fraser 2008). According to the IPCC (IPCC 2012), some of the most common self-regulation mechanisms in CCA and DRR integration are the various models employed in corporate social responsibility (CSR) and the risk insurance mechanisms often found in the businesses model approach (BMA).

\subsubsection{Corporate Social Responsibility}

According to Twigg (2001), CSR goes beyond the traditional market goals of an efficient and economical production of goods and/or services. A major concern of CSR is the set of relationships a company has with: clients, suppliers, and employees; other individuals or groups of individuals that are interested in the behavior of the company both within and outside market; and its needs, values, and goals (Twigg 2001). Frequently CSR is described as involving voluntary advocacy and raising awareness, being flexible in implementation of corporate goals and plans, and ensuring a continuous positive response to public pressure (Lemos and Agrawal 2006; Johannessen et al. 2014). In some circles CSR is also expected to reduce costs and risks, create competitive advantage, and build reputation and legitimacy (Agrawala et al. 2011; IPCC 2012). For governance in CCA and DRR integration, the main types of CSR anticipated are: 
- Philanthropic: donations and grants to organizations, groups, or beneficiaries working in CCA and DRR;

- Contractual: legal obligations entered into with other organizations or groups to carry out work for public benefit; sponsorship of other organizations or groups;

- Adversarial: responses to lobbying and public statements about the human and environmental impact of business activities undertaken to protect reputation and profitability; and

- Unilateral: noncommercial actions undertaken by business independently of other actors (Twigg 2001).

Other usual responsible forms of corporate social responsibility are the protection of employees and operations in risk-prone areas, social justice measures, and longterm business relationships with suppliers (Sarmiento et al. 2014). Notwithstanding all these genuine intentions of responsibility or the generation of benefits, CSR is not altruism, and its main and ultimate concerns are the bottom line of profitability and the direct and indirect benefits to the business. For market actors, solving climate- and climate change-related problems is a desirable by-product not an inherent purpose (Twigg 2001).

\subsubsection{Risk Insurance Mechanisms as a Businesses Model Approach}

Risk insurance mechanisms such as the BMA represent a climate-related risk transfer through which market actors pursue the alignment of CCA and DRR integration with operational and strategic goals (IPCC 2012). Risk insurance mechanisms estimate and price climate change-related risks with a good potential for absorbing the financial burden of disasters. In France, insurance companies provided coverage against climate-related events, collecting the insurance premiums and handling claims and payouts in case of damages (Botzen and van den Bergh 2008). In Bolivia, India, Mongolia, Sudan, Ethiopia (LinneroothBayer et al. 2007; Warner et al. 2007; Davies et al. 2009; Warner et al. 2009), and the Caribbean (Lashley and Warner 2013), a micro-insurance system has been provided for the financial coverage of climate-related risks that impact low-income households and small farmers. Similarly, the municipality of Manizales, Colombia, established a collective insurance policy with an insurance company to protect lower socioeconomic classes from climate-related events. The municipality facilitated the collection of payments, while the insurance company covered any disaster damage to each property according to its rateable value (GDCRR 2011). Risk insurance is also an important element for government policy and development (Sarmiento et al. 2014). In France the national government acted as a guarantor for damages exceeding the payment ability of insurance companies, and set insurance coverage by law (Botzen and van den Bergh 2008).

Despite positive examples, there are some potential negative aspects of the BMA to consider. These investments affect income and consumption and preclude the use of funds for other productive purposes such as investment in education or support to sustainability, livelihood, and income. Additionally, these investments cannot support all types of loss and damage related to climate extremes and change. For example, these investments might be not useful in case of foreseeable and widespread frequent climate-induced hazards such as annual flooding. For these types of risks, resilience-building and preventive measures would represent more cost effective coping ways (Lashley and Warner 2013).

\subsection{Social Domain}

Social actors are private, self-governing organizations (or individuals) composed of voluntary membership and supported by not-for-profit contributions, operating outside the boundaries of state and market (Allen 2006). Climate change poses risks to resources, livelihood, and human settlements, and forces social actors to adapt to conditions of limited resources, identify problems and potential solutions collectively, and join in common actions (Allen 2006; Rojas Blanco 2006).

\subsubsection{Community-Based Initiatives}

CBIs are nonstructural measures enacted by local communities to reach collective goals of CCA and DRR (Allen 2006; Rojas Blanco 2006). For governance in CCA and DRR integration, CBIs provide opportunities for individuals and communities to gain practical problem-solving skills, strengthen social capital, target local scale issues, exploit local resources, increase community participation, and recognize context-specific factors that merit attention (Rojas Blanco 2006). CBIs facilitate community empowerment and encourage the bottom-up transmission of ideas (Van Aalst et al. 2008). In the Philippines, CBIs such as Community-Based Disaster Preparedness (CBDP) have been instrumental in formulating local CCA strategies, which also became linked to wider local development issues (Allen 2006). In fact, a link to local development goals, for example, water, ecosystems, education, and health (Allen 2006), and a focus on contextual and subjective experiences of vulnerability and resilience (Maskrey 2011; Kelman et al. 2015) are considered the only ways for CBIs to be successful.

When connected to DRR, social innovation such as community-based adaptation experiences (Satterthwaite 2011) or initiatives that encourage low-carbon economy 
transition as developed in UK (Seyfang and Haxeltine 2012) might represent fruitful examples of CBIs pursuing adaptive goals. These initiatives experiment sociotechnical transformations and change through adaptive practices related to energy, transport, food, agriculture, environmental management, and livelihood.

\subsubsection{Vulnerable Groups}

Vulnerability is dynamic and varies across temporal and spatial scales. It depends on socioeconomic, geographic, demographic, cultural, political, and environmental factors. Individuals and communities are differentially vulnerable based on inequalities expressed through levels of wealth and education, disability, health, gender, age, class, and other social and cultural characteristics (IPCC 2012). For governance that integrates CCA and DRR, key aspects to target when considering strategies, policies, and plans would be the identification of the differentiated social impacts of climate change based on gender, age, disability, ethnicity, geographical location, livelihood, and migrant status, among others (IPCC 2012). However, populations are often considered as homogeneous, which neglects differences in vulnerability to climate-related risks (DomineyHowes et al. 2013).

In some contexts, marginalization and limitation in accessing resources and labor shape women's vulnerability and lead to violence, isolation, and inequality (Fordham 1998). But the capacities of women in managing climate change-related risks and hazards are increasingly acknowledged worldwide. Experiences of women leading local communities with CCA and DRR integration projects have been reported in Nepal, Tajikistan, and western and southern Africa (UNISDR 2008). In Honduras, Garifuna women led and organized community-based activities for the repair of houses, businesses, and public buildings after the Hurricane Mitch (1998), and targeted DRR and livelihood opportunities at the same time (IPCC 2012). Gero et al. (2010) report the empowerment of women into community-based projects of CCA and DRR integration in Samoa. Accordingly, given the strong gender roles existing in many Pacific cultures, some projects have been characterized by great women sensitivity. For example, single gender workshops ensured both women and men express their opinions freely, as well as the women's role in village life was recognized. This sensitivity allowed avoiding the implementation of projects following the traditional village governance structure. If implementation was via this structure, women's role would be limited to prepare food and refreshments for the outsiders, excluding them from participating in project activities (Gero et al. 2010).

The natural hazards and disaster risk literature considers children and youth as vulnerable to climate change and related disasters (Mitchell and Borchard 2014; Cumiskey et al. 2015; Ronoh et al. 2015). Their agency remains significantly underestimated in DRR and often play a limited role in governance issues. Yet their creativity, innovation, and open-mindedness have the potential to share, contextualize, disseminate, and communicate knowledge through formal and informal networks, as well as to inform protective decision making and advocate for change (Mitchell and Borchard 2014; Cumiskey et al. 2015). For example, in disaster-prone areas of Santo Domingo, children and youth brought energy and longevity to some adaptation projects through activities such as playing, school training, sports, and music. Their involvement led to positive social results useful for DRR, and diminished tensions and gang violence between neighborhoods (Pelling 2011).

Changes in extreme events and in climate change-related impacts influence directly or indirectly the disability status of individuals and communities. Preexisting disability conditions can also exacerbate the impact of climate-related events (IPCC 2012). The SFDRR has established people with disabilities and their advocacy organizations as legitimate stakeholders and actors in the design and implementation of international disaster risk reduction policies (Stough and Kang 2015; UNISDR 2015). But continued efforts are still necessary for the empowerment of people with disabilities in CCA and DRR integration.

State actors could strengthen their legitimacy and advocacy by enacting collaborative mechanisms that provide accessible procedures and services, and at the same time establish technology, information, communication, and collaboration channels with development and civil protection departments (IPCC 2012). Other essential actions are the improvement of livelihood conditions, the negotiation of an adequate design for buildings and public spaces, as well as preparation, education, and training about climate-related issues (Alexander et al. 2012).

Indigenous groups are vulnerable to climate change due to their location in areas at risk and their dependence on primary production and natural resources (IPCC 2012). Findings from Mercer's 2010 fieldwork among indigenous communities in Papua New Guinea challenge the practical need for CCA and DRR integration among indigenous groups. She argues that these groups perceive climate change as just one of the underlying vulnerability factors that contribute to the increased impact of environmental hazards. Indigenous knowledge provides valuable information about local climate change-related risks, for example in Vanuatu (Walshe and Nunn 2012), southern East Asia (Hiwasaki et al. 2014), or Papua New Guinea (Kelman et al. 2009; Mercer 2010). Understanding indigenous knowledge makes it possible to identify 
traditional livelihood practices that potentially lead to climate change-related risks and hazards. Rather than target CCA or DRR, indigenous groups identify the community's needs, such as land use challenges and improvements, which automatically and simultaneously support CCA and DRR strategies (Kelman et al. 2009). Mercer (2010) questioned whether CCA and DRR integration just reinvents the wheel and whether the line dividing CCA and DRR is more theoretical than practical. This example offers a different perspective on the practical need of CCA and DRR integration. It also confirms that CCA and DRR strategies cannot be separated from their wider contextual issues. For example, in drought-prone areas of Kenya and Ethiopia, indigenous groups, supported by nongovernmental organizations (NGOs), planned and built sand dams to be used as artificial aquifers in dry periods. This initiative successfully coped with existing climate fluctuations and reduced climate change-related risks. The project also had positive effects on livelihoods-for example by reducing the time spent on water collection (Van Aalst et al. 2008).

\subsubsection{Nongovernmental Organizations}

Nongovernmental organizations are important actors in CCA and DRR integration (IPCC 2012). The flexibility characteristic of NGOs speeds up processes and actions through bypassing formal bureaucracy; the grassroots and participative approach of NGOs and their adaptable approach to mission and objective are additional advantages (Allen 2006; Dodman and Satterthwaite 2008; Djalante et al. 2011). In CCA and DRR integration, NGOs carry out fundraising for risk-sensitization campaigns, provide legal assistance, engage in alliance building and advocacy work, present requests by local communities to their government's officials, and facilitate interaction with market actors (Dodman and Satterthwaite 2008). As Oxfam GB does in Haiti and Santo Domingo (Pelling 2011) or as the Red Cross and Caritas do in Indonesia (Djalante and Thomalla 2012), NGOs help to fill gaps in implementation by state actors, supporting CBIs in increasing local livelihood and development. In the Pacific Islands, NGOs have helped to undertake adaptive initiatives through training, plan development, simulation exercises, and community education and awareness, coupled with hard infrastructure solutions such as shoreline protection (Gero et al. 2011b).

Increasingly $\mathrm{NGO}$ are reconsidering their attitude towards government financial support out of concern that they may become too reliant on contracts and grants with state actors (Melo Zurita et al. 2015). This may be a costeffective approach for state actors, but it can also represent a strategic form of increased state control of previously independent actors. Whether the "outsourced" trend in government funding represents a permanent and growing shift on the part of NGOs away from the needs of the communities they traditional serve towards the supply of state requests remains unclear (Melo Zurita et al. 2015).

\subsection{Arrangements Bridging State, Market, and Social Domains}

The previous contents have considered main actors intervening in governance of CCA and DRR integration. These actors use some arrangements bridging each other for enacting initiatives and creating partnerships. The following subsections report some examples of three main arrangements emerging in governance according to the literature review.

\subsubsection{Public Private Partnerships}

Public Private Partnerships (PPP) are increasingly seen as motivators of private investments in projects that lack public funding. PPPs have the potential to expand the range of service providers beyond traditional public sector monopolies, and to inject relative efficiency, dynamism, innovation, increased access, quality improvement, and greater consumer responsiveness (Lemos and Agrawal 2006; IPCC 2012). In CCA and DRR integration, PPPs have recently emerged due to a better understanding of increasing hazard vulnerabilities for market assets (Johannessen et al. 2014). Usually CSR works in partnerships such as PPPs to foster public benefits (Twigg 2001), for example by financially supporting the initiatives of state actors in disaster education, prevention, and research (Johnson et al. 2011). Meanwhile, risk insurance companies provide incentives for climate-related DRR in the public sector through programs that raise awareness and promote risk education, encourage pricing risk, create insurance programs, and directly finance DRR (Warner et al. 2009; IPCC 2012).

One of the main risks of PPPs is that they might be trapped in a false position by an opportunistic search for immediate financial results. For example, in Africa, any tenders assigned by governments to the private sector for a quick response to climate-related risk challenges are fraught with political interference and corruption, and run the risk of resulting in jobs of questionable quality and limited local benefit (van Niekerk et al. 2015).

\subsubsection{Private-Social Partnerships}

Private-social partnerships emphasize individual incentives that initially act as market-oriented entities. These PSPs provide time- and place-specific solutions for social actors, allow an equitable allocation of benefits, and help to 
overcome democratic deficits potentially associated with market (Lemos and Agrawal 2006). Market actors have provided examples of PSPs for CCA and DRR integration. Through CSR, market actors develop alliances with, become members of, and create new, associated NGOs, as well as finance NGOs' campaigns to promote "green" markets, environmental well-being, and responsible behavior (Twigg 2001; Johnson et al. 2011). Insurance companies increasingly participate in PSPs and work closely with farmers. For example, in a PSP with smallholder farmers in Malawi, insurance firms have developed an adverse climate/weather insurance system based on indexing historical records of drought. When the index reaches a threshold, regardless of actual losses, farmers can collect on their insurance premium, with the funds being reinvested in future crop cycles (Davies et al. 2009). One of the major risks in PSPs (for example, between NGOs and market actors) is that NGOs may divert their energy from social goals towards exclusive and profitable market goals, which acts against the interests of local communities or common benefits (Twigg 2001).

\subsubsection{Comanagement}

Arrangements such as comanagement (CM) among state and social actors are helpful in sharing responsibilities for public issues (Carlsson and Berkes 2005). By means of $\mathrm{CM}$, CBIs can confront state actors and begin to regulate issues and create space for social initiatives by decentralizing regulation and targeting place-oriented goals (Lemos and Agrawal 2006; Collier et al. 2009). Arrangements for $\mathrm{CM}$ can be enacted, for example, for land use regulation and soil fertility restoration, infrastructure provision, development of building codes and standards, and increased access to funding for development projects and improved water management (Rojas Blanco 2006; Satterthwaite 2011). By arranging for the joint action of CBIs and national/local DRR committees, adaptive education and training activities have been reported in Fiji and Samoa (Gero et al. 2010, 2011a, 2011b) as well as in Jakarta and Vietnam (Van Aalst et al. 2008). In these cases, NGOs have supported the entrance of communities into government arenas. In the Pacific Islands, faith-based organizations have developed a similar NGO role by providing pastoral care and raising awareness and training (Gero et al. 2010). CM also enacts capacity building in urban areas; for instance, inhabitants in informal urban settlements have shared the process of upgrading slum and squatter neighborhoods with local governments by providing infrastructure, services, and improved housing in areas subject to climate change-related risks (Dodman and Satterthwaite 2008). However, CM runs the risk of privileging influential positions within local communities or state actors. For example, CM can become a rhetorical tool that increases government legitimacy and manages conflicts with no devolution of agency (Djalante et al. 2011), instead coopting local community leaders through exclusive relations and reiterative regulative and control forms (Allen 2006).

\section{A Conceptual Governance Framework for CCA and DRR Integration}

Figure 1 summarizes findings from our literature review, and presents a conceptual governance framework for CCA and DRR integration. This framework includes various configurations of state, market, and social actors, and includes bridging arrangements between the three major types of actors. A number of representative actors cross administrative boundaries (for example, scientific organizations or international NGOs) or are unique and contextual (for example, indigenous groups, CBIs, or more formal arrangements to include local communities). Length constraints did not allow including all the actors and arrangements potentially or actually involved in governance of CCA and DRR integration. This article did not consider the whole body of international or transnational actors and partnerships, although it has mentioned international scientific organizations. The article also did not specifically take into account other vulnerable actors, for example Lesbian, Gay, Bisexual, Transgender, Queer, Questioning and Intersex (LGTBQI) groups (DomineyHowes et al. 2013; McSherry et al. 2015), homeless persons (Wisner 1998), or prisoners (Gaillard and Navizet 2012). All of these groups require more in-depth and explicit analysis in the academic literature and in policy formation.

This framework has an exploratory form. The authors are aware that governance in CCA and DRR integration has a complex and porous nature. Refinement is required according to site- and context- specific variables (for example, the exposure to single or multiple risks, and the frequency, intensity, or extension of single or multiple risks), or formal and informal norms (for instance, experiences, perceptions, or social construction of vulnerability and risk) or networks (such as the involvement of non state actors, or socioeconomic, political, and cultural interactions). Accordingly, future application can revise and improve the framework.

Furthermore, the article did not aim to idealize the monolithic and formal aspects of governance at the risk of neglecting the multiple-sometime contradictory and conflicting-facets each actor may assume. But the article affirms the proposition that governance is not a neutral and unproblematic exercise of technical analysis and calculated 
Fig. 1 A conceptual governance framework for CCA and DRR integration. Source Modified from Lemos and Agrawal (2006, p. 310)

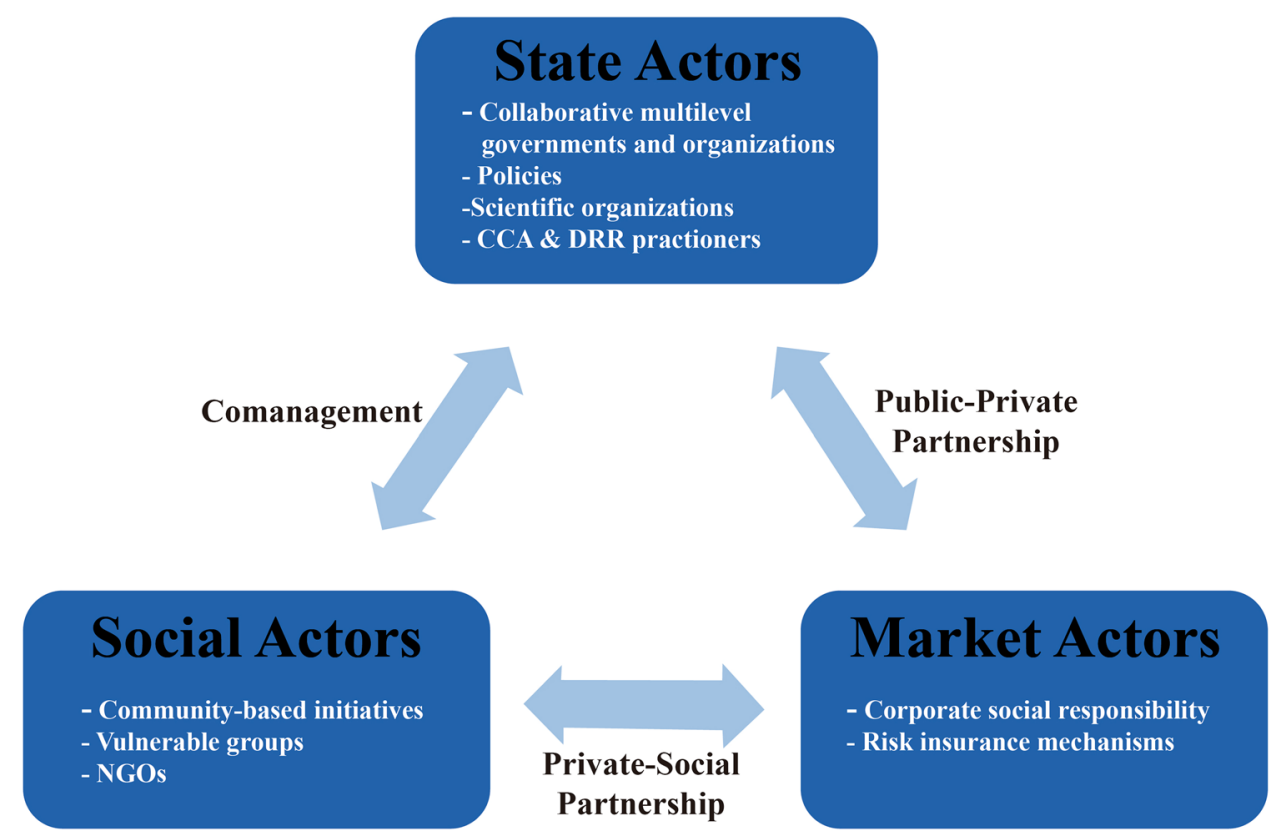

interventions (Lim 2011). In fact, governance has a "Janus face" (Swyngedouw 2005), which might divert the decision-making process from collective goals and benefits towards the legitimization of privileged actors which have ambiguous goals and priorities.

Accordingly, the IPCC's report (IPCC 2012), together with the SFDRR (UNISDR 2015) and SDG's goals (United Nations Department of Economic and Social Affairs 2015), recommends enlarged roles for nonstate actors and the creation of mutual partnerships, as well as the strengthening of governance. This recommendation might not be just a way to give a greater voice to less influential actors. Rather, it might represent a way for influential actors to enhance their political positions or facilitate inequality, for example by allowing greater control in the decision-making process (Lemos and Agrawal 2006).

Therefore, while the involvement of nonstate actors can lead to significant successful opportunities in governance of CCA and DRR integration, monitoring arbitrary and ambiguous exercises, potentially occurring and supporting influential positions, is necessary.

\section{Conclusion}

The article discusses and conceptualizes CCA and DRR integration through a governance lens. Governance in CCA and DRR integration is a varied and complex issue that involves a set of state, market, and social actors, and bridging arrangements such as PPPs, PSPs, and CM. These actors and arrangements are summarized into a conceptual governance framework. The descriptive model created by literature review has an explorative form, which must be refined according to site- and context-specific variables, norms, or networks. With reasonable prudence, this local awareness promotes an initial application of the framework to different contexts. Scholars may adopt the framework as a roadmap with which to corroborate the existence of a theoretical and empirical body of knowledge on governance of CCA and DRR integration. The article is the first output of doctoral research ${ }^{1}$ that investigates the governance of CCA and DRR integration in Australia, where climate change is an actively debated topic in politics and society and a challenging socioeconomic issue (Forino et al. 2014). According to the aforementioned contents, future comprehensive analysis of governance of CCA and DRR integration should continue to investigate actors and bridging arrangements, in both theoretical and empirical ways. Who are actors potentially and actually involved in governance; how their expected outcomes and goals converge or diverge; how and through which mechanisms actors interact; and who are actors with influential or marginal positions in decision-making, implementation, and action are questions to be posed. Eventually, answers to these questions would allow refining and improving the conceptual governance framework, and providing a more holistic picture of CCA and DRR integration.

Acknowledgments Giuseppe Forino is supported by a PhD scholarship from the University of Newcastle. Thanks are due to the comments provided in the following meetings: the seminars by the School of Architecture and Built Environment, University of Newcastle; the ANDROID Residential Doctoral School, 5th International

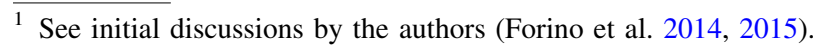


Conference on Building Resilience, Newcastle, 15-17 July 2015; and the session "Cross-sectorial and Multi-scalar Perspectives of Climate Change Adaptation and Disaster Risk Reduction Integration," Fifth EUGEO Congress, Budapest, 30 August-2 September 2015. Giuseppe Forino thanks Sara Bonati for her very helpful comments on an initial draft of the article. The authors thank the anonymous referees and the editors for their comments, which substantially improved the article.

Open Access This article is distributed under the terms of the Creative Commons Attribution 4.0 International License (http://crea tivecommons.org/licenses/by/4.0/), which permits unrestricted use, distribution, and reproduction in any medium, provided you give appropriate credit to the original author(s) and the source, provide a link to the Creative Commons license, and indicate if changes were made.

\section{References}

Agrawala, S., M. Carraro, N. Kingsmill, E. Lanzi, M. Mullan, and G. Prudent-Richard. 2011. Private sector engagement in adaptation to climate change: Approaches to managing climate risks. $O E C D$ Environment Working Papers. Article no. 39.

Alexander, D., J.C. Gaillard, and B. Wisner. 2012. Disability and disaster. In The Routledge handbook of hazards and disaster risk reduction, ed. B. Wisner, JC Gaillard, and I. Kelman, 413-423. New York: Routledge.

Allen, K.M. 2006. Community-based disaster preparedness and climate adaptation: Local capacity-building in the Philippines. Disasters 30(1): 81-101.

Australian Emergency Management Committee (AEMC). 2010. National Emergency Risk Assessment Guidelines.

Becker, P. 2012. The importance of integrating multiple administrative levels in capacity assessment for disaster risk reduction and climate change adaptation. Disaster Prevention and Management 21(2): 226-233.

Becker, P., M. Abrahamsson, and M. Hagelsteen. 2013. Parallel structures for disaster risk reduction and climate change adaptation in Southern Africa. Jàmbá: Journal of Disaster Risk Studies 5(2): 1-5.

Begum, R.A., Md.S.K. Sarkar, A.H. Jaafar, and J.J. Pereira. 2014. Toward conceptual frameworks for linking disaster risk reduction and climate change adaptation. International Journal of Disaster Risk Reduction 10(Part A): 362-373.

Birkmann, J., and J. Pardoe. 2014. Climate change adaptation and disaster risk reduction: Fundamentals, synergies and mismatches. In Adapting to climate change: Lessons from natural hazards planning, ed. B.C. Glavovic, and G.P. Smith, 41-56. Dordrecht: Springer.

Birkmann, J., and R. Mechler. 2015. Advancing climate adaptation and risk management. New insights, concepts and approaches: What have we learned from the SREX and the AR5 processes? Climatic Change 133(1): 1-6.

Birkmann, J., and K. von Teichman. 2010. Integrating disaster risk reduction and climate change adaptation: Key challenges-Scales, knowledge, and norms. Sustainability Science 5(2): 171-184.

Botzen, W.J., and J.C. van den Bergh. 2008. Insurance against climate change and flooding in the Netherlands: Present, future, and comparison with other countries. Risk Analysis 28(2): 413-426.

Bradford, J., and E.D.G. Fraser. 2008. Local authorities, climate change and small and medium enterprises: Identifying effective policy instruments to reduce energy use and carbon emissions. Corporate Social Responsibility and Environmental Management 15(3): 156-172.
Briceño, S. 2015. Looking back and beyond Sendai: 25 years of international policy experience on disaster risk reduction. International Journal of Disaster Risk Science 6(1): 1-7.

Carlsson, L., and F. Berkes. 2005. Co-management: Concepts and methodological implications. Journal of Environmental Management 75(1): 65-76.

Cissé, G. 2013. Water-related disaster management and adaptation to climate change: Bridges and challenges? Water International 38(1): 11-16.

Collier, W. M., K.R. Jacobs, A. Saxena, J. Baker-Gallegos, M. Carroll, and G.W. Yohe. 2009. Strengthening socio-ecological resilience through disaster risk reduction and climate change adaptation: Identifying gaps in an uncertain world. Environmental Hazards 8(3): 171-186.

Council of Australian Governments. 2009. National Partnership Agreement on Natural Disaster Resilience. http://www.federalfi nancialrelations.gov.au/content/npa/environment/natural_disaster_ resilience/national_partnership.pdf.

Council of Australian Governments. 2011. National Strategy for Disaster Resilience Building our nation's resilience to disasters. https://www.coag.gov.au/sites/default/files/national_strategy_dis aster_resilience.pdf.

Cumiskey, L., T. Hoang, S. Suzuki, C. Pettigrew, and M.M Herrgård. 2015. Youth participation at the Third UN World Conference on disaster risk reduction. International Journal of Disaster Risk Science 6(2): 150-163.

Davies, M., B. Guenther, J. Leavy, T. Mitchell, and T. Tanner. 2009. Climate change adaptation, disaster risk reduction and social protection: Complementary roles in agriculture and rural growth? IDS Working Papers 320: 1-37.

Department of Climate Change and Energy Efficiency. 2007. National Climate Change Adaptation Framework. https://www. environment.gov.au/system/files/resources/eaaf0350-9781-4006957c-a5801fadc466/files/nccaf.pdf.

Djalante, R. 2012. Adaptive governance and resilience: The role of multi-stakeholder platforms in disaster risk reduction. Natural Hazards and Earth System Science 12(9): 2923-2942.

Djalante, R. 2013. Identifying drivers, barriers and opportunities for integrating disaster risk reduction and climate change adaptation in Indonesia: An analysis based on the earth system governance framework. In Climate change and disaster risk management, ed. W.L. Filho, 131-147. Berlin Heidelberg: Springer.

Djalante, R., and F. Thomalla. 2012. Disaster risk reduction and climate change adaptation in Indonesia: Institutional challenges and opportunities for integration. International Journal of Disaster Resilience in the Built Environment 3(2): 166-180.

Djalante, R., C. Holley, and F. Thomalla. 2011. Adaptive governance and managing resilience to natural hazards. International Journal of Disaster Risk Science 2(4): 1-14.

Djalante, R., C. Holley, F. Thomalla, and M. Carnegie. 2013. Pathways for adaptive and integrated disaster resilience. Natural Hazards 69(3): 2105-2135.

Dodman, D., and D. Satterthwaite. 2008. Institutional capacity, climate change adaptation and the urban poor. IDS Bulletin 39(4): 67-74.

Dominey-Howes, D., A. Gorman-Murray, and S. McKinnon. 2013. Queering disasters: On the need to account for LGBTI experiences in natural disaster contexts. Gender, Place and Culture 21(7): 905-918.

Duit, A., and V. Galaz. 2008. Governance and complexity - Emerging issues for governance theory. Governance 21(3): 311-335.

Duit, A., V. Galaz, K. Eckerberg, and J. Ebbesson. 2010. Governance, complexity, and resilience. Global Environmental Change 20(3): 363-368.

Fordham, M.H. 1998. Making women visible in disasters: Problematising the private domain. Disasters 22(2): 126-143. 
Forino, G., J. von Meding, G. Brewer, and T. Gajendran. 2014. Disaster risk reduction and climate change adaptation policy in Australia. Procedia Economics and Finance 18: 473-482.

Forino, G., J. von Meding, and G.J. Brewer. 2015. A hybrid governance framework for climate change adaptation (CCA) and disaster risk reduction (DRR) in Australia. In Proceedings ANDROID Residential Doctoral School 5th International Conference on Building Resilience, Newcastle, Australia, 15-17th July 2015, ed. S. Perera, T. Gajendran, and A. Revez, 352 (paper $15)$.

Gaillard, J.C. and F. Navizet. 2012. Prisons, prisoners and disaster. International Journal of Disaster Risk Reduction, 1: 33-43.

GDCRR (German Committee for Disaster Reduction). 2011. Adaptive disaster risk reduction. Enhancing methods and tools of disaster risk reduction in the light of climate change. DKKV Publication Series 43. Bonn.

Gero, A., K. Meheux, and D. Dominey-Howes. 2010. Disaster risk reduction and climate change adaptation in the Pacific: The challenge of integration. Sydney: University of New South Wales.

Gero, A., K. Méheux, and D. Dominey-Howes. 2011a. Integrating community based disaster risk reduction and climate change adaptation: Examples from the Pacific. Natural Hazards and Earth System Science 11(1): 101-113.

Gero, A., K. Méheux, and D. Dominey-Howes. 2011b. Integrating disaster risk reduction and climate change adaptation in the Pacific. Climate and Development 3(4): 310-327.

Heazle, M., P. Tangney, P. Burton, M. Howes, D. Grant-Smith, K. Reis, and K. Bosomworth. 2013. Mainstreaming climate change adaptation: An incremental approach to disaster risk management in Australia. Environmental Science \& Policy 33:162-170.

Hiwasaki, L., E. Luna, Syamsidik, and R. Shaw. 2014. Process for integrating local and indigenous knowledge with science for hydro-meteorological disaster risk reduction and climate change adaptation in coastal and small island communities. International Journal of Disaster Risk Reduction 10(Part A): 15-27.

Howes, M., P. Tangney, K. Reis, D. Grant-Smith, M. Heazle, K. Bosomworth, and P. Burton. 2015. Towards networked governance: Improving interagency communication and collaboration for disaster risk management and climate change adaptation in Australia. Journal of Environmental Planning and Management 58(5): 757-776

Huq, S., S. Kovats, H. Reid, and D. Satterthwaite. 2007. Editorial: Reducing risks to cities from disasters and climate change. Environment and Urbanization 19(1): 3-15.

IPCC (Intergovernmental Panel on Climate Change). 2012. Special report on managing the risks of extreme events and disasters to advance climate change adaptation, ed. CB Field, V Barros, TF Stocker, D Qin, DJ Dokken, KL Ebi, and MDK Mastrandrea. Cambridge: Cambridge University Press.

IPCC (Intergovernmental Panel on Climate Change). 2014. Climate change 2014: Impacts, adaptation, and vulnerability. Part A: Global and sectoral aspects, ed. C.B. Field, and M. Van Aalst. Cambridge: Cambridge University Press.

Ireland, P. 2010. Climate change adaptation and disaster risk reduction: Contested spaces and emerging opportunities in development theory and practice. Climate and Development 2(4): 332-345.

Jessop, B. 1998. The rise of governance and the risks of failure: The case of economic development. International Social Science Journal 50(155): 29-45.

Johannessen, ̊., A. Rosemarin, F. Thomalla, A.G. Swartling, T. Stenström, and G. Vulturius. 2014. Strategies for building resilience to hazards in water, sanitation and hygiene (WASH) systems: The role of public private partnerships. International Journal of Disaster Risk Reduction 10(Part A): 102-115.

Johnson, B.R., E. Connolly, and T.S. Carter. 2011. Corporate social responsibility: The role of Fortune 100 companies in domestic and international natural disasters. Corporate Social Responsibility and Environmental Management 18(6): 352-369.

Johnson, D.A.K., and Y. Abe. 2015. Global overview on the role of the private sector in disaster risk reduction: Scopes, challenges, and potentials. In Disaster management and private sectors. Challenges and potentials, ed. T. Izumi, and R. Shaw, 11-30. Tokyo: Springer.

Kelman, I. 2015. Climate change and the Sendai framework for disaster risk reduction. International Journal of Disaster Risk Science 6(2):117-127.

Kelman, I., and J.C. Gaillard. 2010. Embedding climate change adaptation within disaster risk reduction. In Climate change adaptation and disaster risk reduction: Issues and challenges, ed. R. Shaw, J.M. Pulhin, and J.J. Pereira, 23-46. Bingley: Emerald Group Publishing.

Kelman, I., J.C. Gaillard, and J. Mercer. 2015. Climate change's role in disaster risk reduction's future: Beyond vulnerability and resilience. International Journal of Disaster Risk Science 6(1): $21-27$.

Kelman, I., J. Mercer, and J.J. West. 2009. Combining different knowledges: Community-based climate change adaptation in small island developing states. Participatory Learning and Action 60(1): 41-53.

Kooiman, J., and S. Jentoft. 2009. Meta-governance: Values, norms and principles, and the making of hard choices. Public Administration 87(4): 818-836.

Lashley, J.G., and K. Warner. 2013. Evidence of demand for microinsurance for coping and adaptation to weather extremes in the Caribbean. Climatic Change 133(1): 101-112.

Lemos, M.C., and A. Agrawal. 2006. Environmental governance. Annual Review of Environment and Resources 31(1): 297-325.

Lim, W.-K. 2011. Understanding risk governance: Introducing sociological neoinstitutionalism and foucauldian governmentality for further theorizing. International Journal of Disaster Risk Science 2(3): 11-20.

Linnerooth-Bayer, J., A. Amendola, N. Okada, and P. Shi. 2007. Disaster risk management: Pro-active financing to reduce vulnerability. Environmental Hazards 7(1): 1-6.

Marincioni, F. 2007. Information technologies and the sharing of disaster knowledge: The critical role of professional culture. Disasters 31(4): 459-476.

Maskrey, A. 2011. Revisiting community-based disaster risk management. Environmental Hazards 10(1): 42-52.

McSherry, A., E.J. Manalastas, J.C. Gaillard, and S.N.M Dalisay. 2015. From deviant to Bakla, strong to stronger: Mainstreaming sexual and gender minorities into disaster risk reduction in the Philippines. Forum for Development Studies 42(1): 27-40.

Melo Zurita, M. de L., B. Cook, L. Harms, and A. March. 2015. Towards new disaster governance: Subsidiarity as a critical tool. Environmental Policy and Governance. doi:10.1002/eet.1681.

Mercer, J. 2010. Disaster risk reduction or climate change adaptation: Are we reinventing the wheel? Journal of International Development 22(2): 247-264.

Mercer, J., I. Kelman, F. do Rosario, A. de D. de Jesus Lima, A. da Silva, A.M. Beloff, and A. McClean. 2014. Nation-building policies in Timor-Leste: Disaster risk reduction, including climate change adaptation. Disasters 38(4): 690-718.

Mitchell, P., and C. Borchard. 2014. Mainstreaming children's vulnerabilities and capacities into community-based adaptation to enhance impact. Climate and Development 6(4): 372-381. 
Mitchell, T., and M. van Aalst. 2008. Convergence of disaster risk reduction and climate change adaptation. A review for DFID31st October. http://www.nirapad.org.bd/admin/soft_archive/ 1308126954_Convergence\%20of\%20Disaster\%20Risk\%20Reduc tion $\% 20$ and $\% 20$ Climate $\% 20$ Change $\% 20$ Adaptation.pdf. Accessed 12 Dec 2015.

Mysiak, J., S. Surminski, A. Thieken, R. Mechler, and J. Aerts. 2015. Brief communication: Sendai framework for disaster risk reduction-Success or warning sign for Paris? Natural Hazards and Earth System Sciences Discussions 3(6): 3955-3966.

Nalau, J., J. Handmer, M. Dalesa, H. Foster, J. Edwards, H. Kauhiona, L. Yates, and S. Welegtabit. 2015. The practice of integrating adaptation and disaster risk reduction in the south-west Pacific. Climate and Development. doi:10.1080/17565529.2015. 1064809.

O’Brien, G., P. O'Keefe, J. Rose, and B. Wisner. 2006. Climate change and disaster management. Disasters 30(1):64-80.

Ostrom, E. 2008. Frameworks and theories of environmental change. Global Environmental Change 18(2): 249-252.

Pelling, M. 2011. Urban governance and disaster risk reduction in the Caribbean: The experiences of Oxfam GB. Environment and Urbanization 23(2): 383-400.

Porfiriev, B. 2015. Climate change as a major slow-onset hazard to development: An integrated approach to bridge the policy gap. Environmental Hazards. doi:10.1080/17477891.2015.1019823.

Prno, J., and D.S. Slocombe. 2012. Exploring the origins of "social license to operate" in the mining sector: Perspectives from governance and sustainability theories. Resources Policy 37(3): $346-357$.

Renn, O. 2015. Stakeholder and public involvement in risk governance. International Journal of Disaster Risk Science 6(1): 8-20.

Rhodes, R.A.W. 1996. The new governance: Governing without government. Political Studies 44(4): 652-667.

Rhodes, R.A.W. 2007. Understanding governance: Ten years on. Organization Studies 28(8): 1243-1264.

Rivera, C., and C. Wamsler. 2014. Integrating climate change adaptation, disaster risk reduction and urban planning: A review of Nicaraguan policies and regulations. International Journal of Disaster Risk Reduction 7: 78-90.

Rojas Blanco, A.V. 2006. Local initiatives and adaptation to climate change. Disasters 30(1): 140-147.

Ronoh, S., J.C. Gaillard, and J. Marlowe. 2015. Children with disabilities and disaster risk reduction: A review. International Journal of Disaster Risk Science 6(1): 38-48.

Sarmiento, J.P., G. Hoberman, M. Ilcheva, A. Asgary, A.M. Majano, S. Poggione, and L.R. Duran. 2014. Private sector and disaster risk reduction: The cases of Bogota, Miami, Kingston, San Jose, Santiago, and Vancouver. International Journal of Disaster Risk Reduction 14(Part 3): 225-237.

Satterthwaite, D. 2011. Editorial: Why is community action needed for disaster risk reduction and climate change adaptation? Environment and Urbanization 23(2): 339-349.

Satterthwaite, D. 2015. The SDGs don't adequately spell out cities' role in implementation. http://citiscope.org/habitatIII/commentary/ 2015/10/sdgs-dont-adequately-spell-out-cities-role-implementation\# sthash.572zq3Q5.dpuf. Accessed 29 Nov 2015.

Schipper, L., and M. Pelling. 2006. Disaster risk, climate change and international development: Scopes for, and challenges to, integration. Disasters 30(1): 19-38.

Seyfang, G., and A. Haxeltine. 2012. Growing grassroots innovations: Exploring the role of community-based initiatives in governing sustainable energy transitions. Environment and Planning $C$ : Government and Policy 30(3): 381-400.

Stough, L.M., and D. Kang. 2015. The Sendai framework for disaster risk reduction and persons with disabilities. International Journal of Disaster Risk Science 6(2): 140-149.

Swyngedouw, E. 2005. Governance innovation and the citizen: The Janus face of governance-beyond-the-state. Urban Studies 42(11): 1991-2006.

Thomalla, F., T. Downing, E. Spanger-Siegfried, G. Han, and J. Rockström. 2006. Reducing hazard vulnerability: Towards a common approach between disaster risk reduction and climate adaptation. Disasters 30(1): 39-48.

Twigg, J. 2001. Corporate social responsibility and disaster reduction: A global overview. London: Benfield Greig Hazard Research Centre.

UNDESA (United Nations Department of Economic and Social Affairs). 2015. Sustainable development goals. https://sustaina bledevelopment.un.org/?menu=1300. Accessed 29 Oct 2015.

UNFCCC (United Nations Framework Convention on Climate Change). 2007. Report of the conference of the parties on its thirteenth session-Bali action plan. Bonn: UNFCCC.

UNISDR (United Nations International Strategy for Disaster Reduction). 2005. Hyogo framework for action 2005-2015: Building the resilience of nations and communities to disasters. Geneve: UNISDR.

UNISDR (United Nations International Strategy for Disaster Reduction). 2008. Linking disaster risk reduction and poverty reduction: Good practices and lessons learned. Geneva: UNISDR.

UNISDR (United Nations International Strategy for Disaster Reduction). 2009. Adaptation to climate change by reducing disaster risks: Country practices and lessons. Briefing note 2. Geneva: UNISDR.

UNISDR (United Nations International Strategy for Disaster Reduction). 2015. Sendai framework for disaster risk reduction 20152030. Geneva: UNISDR.

van Aalst, M.K., T. Cannon, and I. Burton. 2008. Community level adaptation to climate change: The potential role of participatory community risk assessment. Global Environmental Change 18(1): 165-179.

van Niekerk, D. 2015. Disaster risk reduction and climate change adaptation: Towards community resilience. In South African environmental law: The governing function of local government, ed. A. Du Plessis. Kenwyn: Juta.

van Niekerk, D., E. Ndlovu, and P. Chipangura. 2015. Experiences of Africa: Status and potentials. In Disaster management and private sectors, ed. T. Izumi and R. Shaw, 83-104. Tokyo: Springer.

Walshe, R.A., and P.D. Nunn. 2012. Integration of indigenous knowledge and disaster risk reduction: A case study from Baie Martelli, Pentecost Island, Vanuatu. International Journal of Disaster Risk Science 3(4): 185-194.

Warner, K., L.M. Bouwer, and W. Ammann. 2007. Financial services and disaster risk finance: Examples from the community level. Environmental Hazards 7(1): 32-39.

Warner, K., N. Ranger, S. Surminski, M. Arnold, J. LinneroothBayer, E. Michel-Kerjan, P. Kovacs, and C. Herweijer. 2009. Adaptation to climate change: Linking disaster risk reduction and insurance. Geneva: UNISDR.

Wisner, B. 1998. Marginality and vulnerability: Why the homeless of Tokyo don't 'count'in disaster preparations. Applied Geography, 18(1): 25-33. 